Gut, 1985, 26, 783-788

\title{
Origin of chronic right upper quadrant pain
}

\author{
J G C KINGHAM AND A M DAWSON \\ From the Department of Gastroenterology, St Bartholomew's Hospital, London
}

SUMMARY We have studied 22 consecutive patients referred for investigation of severe chronic right upper quadrant pain. The majority were women whose symptoms had been present for many years. All had undergone repeated investigations of the pancreatico-biliary, gastrointestinal, urinary, and even gynaecological systems without a satisfactory diagnosis. Most had undergone at least one abdominal operation in an unsuccessful attempt to cure their pain. In 21 of 22 patients the customary pain was completely and reproducibly mimicked by balloon distension of the small or large intestine in at least one site. The trigger sites were jejunum (15), ileum (12), right colon (nine), and duodenum (six). In 12 more than one trigger site was found. Close questioning revealed features of the irritable bowel syndrome in the majority and depression in many though the symptoms were not spontaneously volunteered. Reproduction of pain has provided a convincing demonstration to this difficult group of patients that they have a sensitive gut and allows appropriate management.

Chronic right upper quadrant pain allows greater scope for diagnostic and therapeutic mismanagement than perhaps any other abdominal symptom. When those sufferers with no identifiable cause'-for example, nerve root pain, local malignant or inflammatory disease have been excluded, the remainder have a number of features in common. In particular they suffer flatulent dyspepsia and find their symptoms are aggravated by fatty foods. It is in part these associated symptoms that so frequently and unjustifiably lead to a diagnosis of gall bladder disease. Despite the realisation in recent years that flatulent dyspepsia is equally common in those with or without gall stones, ${ }^{1-3}$ the myth of gall bladder dyspepsia persists. Similarly, it is still commonly held and taught that chololithiasis may cause chronic continuous right upper quadrant pain which again is a fallacy. Gall stones, if they cause pain at all, induce biliary colic which is episodic, severe and brief, only exceptionally lasting more than a few hours. ${ }^{4}$ Another more worrying feature these patients share is the extent to which investigations are pursued and surgical manoeuvres carried out in futile attempts to find or remove the cause of the pain.

That chronic right upper quadrant pain may be either an integral or the sole manifestation of a

Address for correspondence: Dr J G C Kingham, Department of Gastroenterology. St Bartholomew's Hospital, London EC1 7BE.

Received for publication 8 October 1984 functional bowel order is already amply documented. ${ }^{5-11}$ The abundance of such patients habitually attending medical and surgical clinics who have eluded diagnosis implies that this is not common knowledge.

We have prospectively evaluated consecutive patients with chronic right upper quadrant pain referred to our department with particular reference to their gastrointestinal function, in its broadest sense, and their psychological state. Our hypothesis is that these patients are suffering from functional bowel pain akin to the irritable bowel syndrome and we have attempted to show this by balloon distention of the alimentary tract to reproduce their pain.

\section{Methods}

\section{PATIENTS}

All patients referred to the department of gastroenterology between July 1983 and March 1984 because of chronic right upper quadrant pain were included in this study. There were 17 women and five men whose ages ranged from 25-64 years, median 39 years. These 22 patients comprised approximately $1.5 \%$ of all new patients referred to our department during this nine month period. They were not particularly sought out and we did not gain the impression that we saw more or less such patients during this period than during any other. The sources of referral of the 22 patients were 
general practitioners (six), general surgeons (eight), general physicians (five), and gastroenterologists (three).

\section{STUDY PROTOCOL}

All patients were initially assessed in the outpatient clinic. A detailed history and physical examination failed to reveal any local, musculoskeletal or neurological cause of their complaint. The notes and radiographs from other institutions (often voluminous) were then reviewed. None of our 22 patients had escaped previous investigations; liver function tests, full blood counts, barium studies or endoscopy and imaging investigations of the biliary tree had been carried out at least once on each patient and had been found essentially normal. In view of the nature of this study we felt it imperative to exclude a pancreaticobiliary tract or gastrointestinal tract lesion with complete certainty; thus if there was any doubt about normality in previous investigations, or if much time had elapsed since their performance, they were either repeated or a more descriminant investigation performed. In particular all patients had endoscopic retrograde cholangiopancreatograms. After review or repeat of the relevant tests had excluded organic abnormalities, each patient was admitted to the ward for clinical evaluation, assessment of depression and for balloon studies of the upper and lower gut. Depression was assessed at a semi-structured interview using a modification of the Hamilton rating scale. ${ }^{12} 13$ This included all 21 of the items originally devised by Hamilton with three extras: helplessness, hopelessness, and worthlessness.

\section{BALLOON STUDIES: UPPER GUT}

Patients were fasted for six hours before and during the course of these studies. The patient swallowed a weighted $(20 \mathrm{~g})$ latex balloon (London Rubber Industries) attached to two metres of $1.5 \mathrm{~mm}$ diameter radio opaque flexible tubing (Figure). The balloon reached the distal ileum within six to 18 hours. Under radiograph screening the balloon was inflated with air up to a maximum of $40 \mathrm{ml}$ or less if severe pain was induced. Any symptom or pain experienced by the patient, its character, site and radiation was recorded. In particular patients were asked if they recognised typical spontaneous pain. On deflation of the balloon note was made of whether the pain was relieved and how quickly this occurred. If pain had been induced the balloon was reflated to check reproducibility. This procedure was repeated with the balloon sited in the proximal jejunum, the second part of the duodenum and the lower end of the oesophagus (Figure). The total radiograph screening time for each patient was less

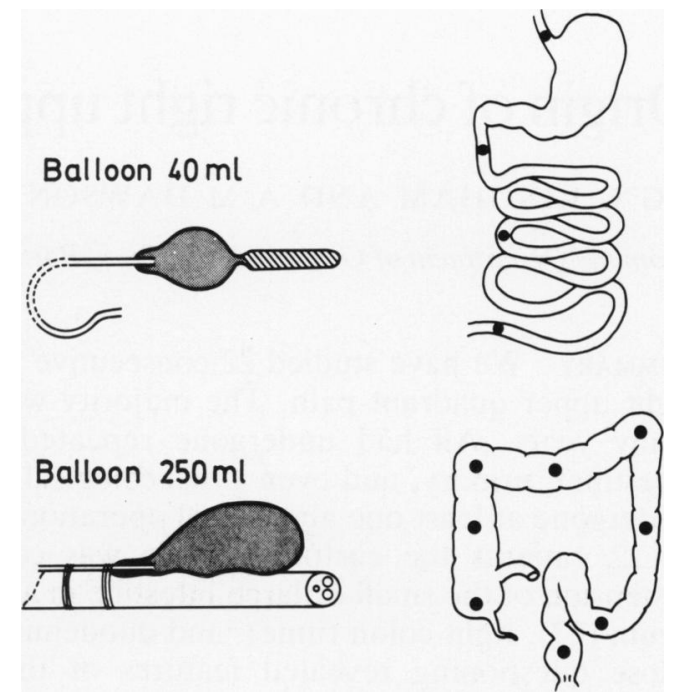

Figure Small latex balloon with mercury weighted bag on fine radiopaque tubing and colonic balloon taped to colonoscope with schematic representations of upper and lower alimentary tract to show sites of inflation.

than two minutes.

BALLOON STUDIES: COLON

Patients were prepared as for a normal colonoscopy. The procedure was done under light intravenous sedation ( $5 \mathrm{mg}$ diazepam, $50 \mathrm{mg}$ pethidine). An ordinary children's rubber party balloon attached to 1.5 metres of fine polythene tubing was taped alongside the colonoscope (Figure). The colonoscope was introduced as far as the caecum. At this point the effect of the pethidine was reversed by intravenous Naloxone $0.4 \mathrm{mg}$. The balloon was inflated to a maximum of $250 \mathrm{ml}$, or less if severe pain was induced, and any pain, its site, radiation and character recorded as for the other balloon studies. As the colonoscope was withdrawn the balloon was reinflated at eight sites around the colon (Figure) and once again any pain recorded. At the beginning of the study, radiograph screening was used to verify the position of the balloon. It soon became clear that recognisable landmarks within the colon (caecum, flexures) and the ability to see the light through the abdominal wall usually made screening unnecessary.

\section{Results}

CLINICAL OBSERVATIONS

The patients were predominantly women in early middle age. Their symptoms had been present for 
between two and 30 years (median nine years) and occurred in well-defined attacks in 14, but more continuously in eight. The pain often radiated to other sites, most frequently to the back at the level of the right hypochondrium (10) but also the right shoulder blade area (five), the epigastrium (four), and the right lower quadrant (three), of those whose pain occurred in attacks, in only one did we consider this typical of true biliary colic. In the remainder the long duration of the pain, usually a day or more, and its quality made a diagnosis of biliary colic unlikely. Only two patients had not seen a hospital specialist before; the other 20 had previously seen a total of 76 consultants for their pain. All 22 had been previously investigated, in most cases exhaustively and repeatedly; of imaging studies alone, 72 pancreaticobiliary procedures (oral cholocystrogram, intravenous cholangiogram, ERCP, ultrasound, CT) 53 barium radiographs, 25 gastrointestinal endoscopies and 12 intravenous urograms had been undertaken. Understandably with so many investigations some abnormalities had been observed, though the passage of time had shown these abnormalities to be unrelated to the patients' symptoms. For instance, five patients had been found initially to have gall stones but the pain had continued unchanged despite cholecystectomy. Such pain though did not have the features of biliary colic, but was of the flatulent dyspeptic type. Similarly, several patients were found to have small ovarian cysts, retroverted uterus, gastritis, duodenitis, hiatus hernia and colonic diverticulosis but medical or surgical treatment for such abnormalities left the symptoms unaltered. It was noteworthy how often tests had been repeated despite complete normality .on the first and subsequent occasions. Full blood count, ESR, and liver function tests were consistently normal in all patients. Sixteen patients had undergone 38 surgical operations in attempts to either cure or diagnose their pain. In none had this been successful in the long term. The operations most frequently performed had been cholecystectomy (10) and appendicectomy (12). The other 16 operations included ovarian cystectomy, ventral suspension of the uterus, exploratory laparotomy, nerve excision and sundry others. In only five of 10 cholecystectomies were gall stones or gall bladder disease found. All but one appendicectomies were carried out for 'grumbling appendicitis' and only in the one acute case was there histological evidence of inflammation.

\section{BALLOON STUDIES}

Spontaneous right upper quadrant pain was exactly and reproducibly induced in 21 of the 22 patients by balloon distension of at least one area of the small or large intestine (Table). In 12, more than one trigger
Table Sites of balloon for reproduction of typical spontaneous pain in 22 patients with chronic right hypochondrial pain

22 patients with RUQ pain Reproduction of spontaneous pain

\begin{tabular}{|c|c|c|}
\hline Oesophagus & 0 & \\
\hline Duodenum & 6 & $\begin{array}{l}21 \text { of } 22 \text { in } \\
\text { at least one site }\end{array}$ \\
\hline lleum & 12 & \\
\hline Right colon & 9 & $\begin{array}{l}12 \text { of } 22 \\
\text { two or more sites }\end{array}$ \\
\hline Left colon & 0 & \\
\hline
\end{tabular}

area was found to reproduce right upper quadrant pain and the areas were not necessarily in continuity - for example, jejunum and caecum. The areas most commonly shown to be sensitive were the jejunum (15), ileum (12) and right colon (nine); the duodenum (six) was less often sensitive. The distribution of trigger areas within the colon was caecum (eight), ascending (eight), hepatic flexure (six), transverse (three) and splenic flexure (one). In none of these 22 patients could spontaneous right upper quadrant pain be reproduced by balloon distension of the oesophagus or the left colon distal to the splenic flexure.

In about half of those patients in whom the spontaneous right upper quadrant pain typically radiated such radiation was also induced by balloon distension: to the back in five of 10 , to the right shoulder blade in two of five, to the epigastrium in three of four and to the right lower quadrant in two of three.

As would be expected, all patients were aware of some pain or sensations during these procedures which were quite unlike their spontaneous pain, either in site or character. Most commonly these were a sensation of heartburn from the oesophagus, a sickening central ache from the small bowel, lower abdominal wind pains from the colon and a desire to defaecate with rectal distension. In addition, 15 patients experienced pain of the same character as their spontaneous pain though in an unaccustomed abdominal site. The trigger areas responsible for such pain were different from those which triggered the right upper quadrant pain. In particular, left sided colonic distension often caused left sided or lower abdominal pain of recognisable character.

ASSESSMENT OF ASSOCIATED SYMPTOMS

In no patient had a diagnosis of a functional bowel 
disorder been made before referral, though many had prominent symptoms suggesting such a disorder. Paramount amongst these were fat intolerance, flatulence and abdominal distension which were specifically mentioned at the first interview by 18,13 , and 15 patients respectively. Other features characteristic of a functional bowel disorder which were revealed during the interview, though not spontaneously volunteered, included irregular bowel habit in 14, a frequent sensation of incomplete evacuation in 10 , a change in stool pattern in association with the pain in nine, relief of pain by passing flatus or opening the bowels in 12 , and recognition of the pain being related to tension in nine. On the basis of the history we considered 16 of the 22 patients to be suffering from a typical functional bowel disorder (though not classical irritable colon syndrome).

Using the modified Hamilton ${ }^{12}{ }^{13}$ rating scale, we judged four patients to be severely, six moderately, and four mildly depressed. Only eight were considered free of depression. The eight patients with continuous pain had more marked depression (four severe, two moderate, two mild) than the 14 with intermittent pain (four moderate, two mild). There was no correlation between the presence or severity of depression and age, duration of pain and functional bowel complaints.

\section{Discussion}

This study has shown that distension of a part or parts of the gut reproduces typical pain in patients who suffer the syndrome of chronic right upper quadrant pain with fat intolerance and flatulent dyspepsia. The implication of this is that their gut is oversensitive and that they have a functional bowel disorder. This is analogous to the well recognised observation that insufflation of air at sigmoidoscopy will often reproduce the left lower abdominal pain of patients with a spastic colon.

Balloon distension has been used to induce alimentary tract pain since the beginning of the century. Several physiological studies have shown that the gut of normal individuals is sensitive to distension and that the pain produced is referred in well defined patterns. Distension of the oesophagus $^{14} 15$ is perceived retrosternally or in the epigastrium; of the stomach and small intestine ${ }^{16-19}$ in the epigastrium or around the umbilicus; of the colon ${ }^{16} 18$ in the lower central or left abdomen and of the rectosigmoid colon ${ }^{16} 1820$ in the hypogastrium, left iliac fossa, or perineum. Fewer studies have been published on pain referral from biliary tract distension ${ }^{1821}$ but where this has been done the pain was referred predominantly to the epigastrium and occasionally to the right upper quadrant. These data are of course derived from normal subjects. It would be incorrect to assume that the distribution of pain referral from gut distension is the same in normal subjects, those with organic diseases and those with functional gut disorders. ${ }^{10} 11$

There has, until recently, been little information regarding sensitivity to, and pain referral from, gut distension in functional disorders. Dworken ${ }^{22}$ reproduced functional symptoms of pain in the left upper abdomen, arm and praecordium in 11 sufferers by balloon distension of their splenic flexures. He called this the splenic flexure syndrome. In similar manner Ritchie ${ }^{23}$ found patients with classical irritable colon syndrome very sensitive to balloon distension of the sigmoid colon. Balloon inflation to a degree not usually perceptible in a normal subject produced the patients' typical lower left abdominal pain.

More recently Swarbrick et $a l^{10}$ and Moriarty et $a l^{11}$ have shown that functional pains in a variety of abdominal and extra-abdominal sites could be reproduced by balloon distension of the large or small intestine or both. Harvey and Read ${ }^{8}$ have made the same point but using a different technique. Rather than distend the gut, they caused it to contract using cholecystokinin and were able to mimic a typical attack of irritable bowel pain. Levitt's ${ }^{24}$ group showed the sensitivity of the gut to distension in patients with functional abdominal pain by infusing gas into the small intestine. This rarely caused discomfort in normal controls but usually caused severe and typical symptoms in the patients.

The failure to find a biliary tract disorder in our patients is not surprising as chronic right upper quadrant pain of this type, despite popular belief, is not a feature of cholelithiasis or biliary colic. It has been convincingly shown in a number of studies that flatulent dyspepsia and fat intolerance are no more common in those with, or those without, gall stones. ${ }^{1-3}$ Where any abnormality can be shown in patients with such symptoms it is a gut motility disorder ${ }^{25-27}$

A report by Valberg ${ }^{28}$ of putative biliary pain in the presence of an entirely normal biliary tract and liver function is of some interest. The patients described were all young women with chronic intermittent right upper quadrant pain; the majority also had typical symptoms of a functional gut disorder and many had depression or anxiety. When given cholecystokinin the symptoms of right upper quadrant pain were reproduced and this was taken by the authors as evidence of biliary pain. In the light of more recent experience with cholecystokinin, ${ }^{82}$ however, it seems highly probable that the 'biliary pain' of these women was in fact gut pain. 
The history of extensive and fruitless investigations and operations in our patients is by no means unusual. Such observations are commonplace in most reviews of the irritable bowel syndrome. 561130 Similarly our finding of unrecognised depression is not original. Depression has been shown to be a common accompaniment to long standing irritable bowel syndrome ${ }^{6731-33}$ or indeed other disorders manifest by chronic pain. ${ }^{34-36}$ It is unclear whether depression predisposes to intractable functional abdominal pain or vice versa but speculation on this chicken and egg dilemma is probably unrewarding. What seems clear from our observations is that the vicious circle will not be broken until the depression is treated.

The main concern is the medical time, effort and facilities wasted and the detrimental emotional effect on the patient. There is also, though, a financial consideration. On average each patient had 3.5 consultations, 7.3 investigations, 1.7 operations and more than 20 blood and urine tests. There is no reliable way to determine the cost of this to the Health Service but in the British private sector 2 to 3 thousand pounds per patient would be a realistic estimate.

We feel that an accurate history and its correct interpretation will prevent unnecessary investigations in this group of patients and enable them to be given appropriate rather than inappropriate management. There would seem to be a place for tests such as these in the patient who demands or requires further investigation when the clinical diagnosis is functional abdominal pain.

We would like to thank Dr C B Williams and Dr P D Fairclough who performed some of the colonoscopies.

\section{References}

1 Price WH, Gall-bladder dyspepsia. Br Med J 1963; 2: 138-41.

2 Koch JP, Donaldson RM. A survey of food intolerances in hospitalized patients. $N$ Engl J Med 1964; 271: 13: $657-60$.

3 Bainton D. Gallbladder disease. N Engl J Med 1976; 294: 1147-9.

4 French EB, Robb WAT. Biliary and renal colic. $\mathrm{Br}$ Med J 1963; 2: 135-8.

5 Chaudhary NA, Truelove SC. The irritable colon syndrome. $Q$ J Med 1962; 123: 307-22.

6 Waller SL, Misiewicz JJ. Prognosis in the irritablebowel syndrome. Lancet 1969: 2: 753-5.

7 Hislop IG. Psychological significance of the irritable colon syndrome. Gut 1971; 12: 452-7.

8 Harvey RF, Read AE. Effect of Cholecystokinin on colonic motility and patients with the irritable bowel syndrome. Lancet 1973; 1: 1-3.

9 Thompson W Grant. The irritable gut. Baltimore: University Park Press, 1979: 187-200.

10. Swarbrick ET. Hegarty JE. Bat L, Williams CB, Dawson AM. Site of pain from the irritable bowel. Lancet 1980 2: 443-6.

11 Moriarty KJ, Dawson AM. Functional abdominal pain: further evidence that whole gut is affected. $\mathrm{Br}$ Med $\mathrm{J}$ 1982; 284: 1670-2.

12 Hamilton M. A rating scale for depression. J Neurol Neurosurg Psychiat 1960; 23: 56-2.

13 Hamilton $M$. Development of a rating scale for primary depressive illness. Br J Soc Clin Psychol 1967; 6: 278-96.

14 Polland WS, Bloomfield AL. Experimental referred pain from the gastro-intestinal tract. Part 1. The oesophagus. J Clin Invest 1931; 10: 13: 435-52.

15 Hertz AF. The sensibility of the alimentary canal in health and disease. Lancet 1911; 1: 1051-6.

16 Bloomfield AL, Polland WS. Experimental referred pain from the gastrointestinal tract. Part II. Stomach, duodenum and colon. J Clin Invest 1931: 10: 13: 453-73.

17 Bentley FH, Smithwick RH. Visceral pain produced by balloon distension of the jejunum. Lancet 1940; 2: 389-91.

18 Ray BS, Neill CL. Abdominal visceral sensation in man. Ann Surg 1947; 126: 709-24.

19 Jones CM. Digestive tract pain. New York: Macmillan, 1983: 8.

20 Goligher JC, Hughes ESR. Sensibility of the rectum and colon. Lancet 1951; 1: 543-8.

21 Doran FSA. Sites of pain referred from common bile duct. Br J Surg 1967; 54: 599-606.

22 Dworken HJ. Supradiaphragmatic reference of pain from the colon. Gastroenterology 1952; 22: 222-31.

23 Ritchie J. Pain from distension of the pelvic colon by inflating a balloon in the irritable colon syndrome. Gut 1973; 14: 125-32.

24 Lasser RB, Bond JH, Levitt MD. The role of intestinal gas in functional abdominal painn. $N$ Engl J Med 1975; 293: 524-6.

25 Johnson AG. Cholecystectomy and gallstone dyspepsia. Ann R Coll Surg 1975; 56: 69-80.

26 Capper WM, Butler TJ, Kilby JO, Gibson MJ. Gallstones, gastric secretion, and flatulent dyspepsia. Lancet 1967; 1: 413-5.

27 Sekar ASC, Thompson WG, Turner LJ, Barr R. Duodenogastric reflux and gastritis in non-ulcer dyspepsia. [Abstract] Clin Res 1977; 24: 667A.

28 Valberg LS, Jabbari M, Kerr JW, Curtis AC. Ramchand J, Prentice RSA. Biliary pain in young women in the absence of gallstones. Gastroenterology 1971; 60: 1020-6.

29 Dinoso VP, Meshkinpour H, Lorber SH. The response of the sigmoid colon and rectum to exogenous cholecystokinin and secretin. Gastroenterology 1972; 62: 844.

30 Lane $D$. The irritable colon and right iliac fossa pain. Med J Australia 1973; 1: 66-7.

31 Young SJ, Alpers DM, Norland CC, Woodruff RA. 
Psychiatric illness and the irritable bowel syndrome. 34 Large RG. The psychiatrist and the chronic pain Gastroenterology 1976; 70: 162-6.

32 Hill OW, Blendis L. Physical and psychological evaluation of 'non-organic' abdominal pain. Gut 1967; 8: 221-9. patient: 172 anecdotes. Pain 1980; 9: 253-63.

35 Blumer D, Heilbronn M. The pain-prone disorder: a clinical and psychological profile. Psychosomatics 1981;

33 Gomez J, Dally P. Psychologically mediated abdominal pain in surgical and medical outpatient clinics. $B r$ Med J 1977; 1: 1451-3. 22: 395-402.

36 Kramlinger KG, Swanson DW, Maruta T. Are patients with chronic pain depressed? Am J Psychiatr 1983; 140: 747-9. 